BRITISH MEDICAL JOURNAL VOLUME 29319 JULY 1986

TABLE II-Anti-HTLV-III/LAV in patients with haemophilia $A$ having treatment with commercial or British factor VIII concentrate

\begin{tabular}{ccccc}
\hline & \multicolumn{2}{c}{ Commercial } & \multicolumn{2}{c}{ British } \\
\cline { 2 - 3 } \cline { 5 - 5 } Year of testing & No tested & No $(\%)$ positive & No tested & No (\%) positive \\
\hline 1978 & 10 & 0 & 2 & 0 \\
1979 & 28 & 0 & 2 & 0 \\
1980 & 70 & $23(33)$ & 2 & 0 \\
1981 & 56 & $28(50$ & 2 & 0 \\
1982 & 72 & $46(64)$ & 8 & 0 \\
1983 & 105 & $69(66)$ & 99 & $1(1)$ \\
1984 & 315 & $215(68)$ & 166 & $18(11)$ \\
\hline
\end{tabular}

TABLE III-Anti-HTLV-I in 401 patients with haemophilia A

\begin{tabular}{lcc}
\hline \multirow{2}{*}{$\begin{array}{l}\text { Serological finding } \\
\text { for HTLV-III }\end{array}$} & \multicolumn{2}{c}{ Anti-HTLV-I } \\
\cline { 2 - 3 } & No tested & No positive \\
\hline Positive & 120 & 0 \\
Negative & 281 & 1 \\
\hline
\end{tabular}

AIDS $^{4}$ and might be represented among the commercial donors. There was no evidence of HTLV-I infection in any patient with the exception of a single Japanese, who was seronegative for HTLVIII/LAV (table III). This finding accords with previous studies," showing that HTLV-I was not transmitted by blood products prepared from pooled plasma. The failure of HTLV-I to transmit was also likely to be due to a relatively low prevalence of infected donors and the presence of high concentrations of neutralising antibody in plasma from any infected donor. ${ }^{10}$

The prevalence of HTLV-III/LAV infection remained comparatively unchanged from 1982 onwards. This may have been due to the exclusion of high risk subjects from the commercial donor panels though this seems unlikely in view of the seroconversions documented in 1983 and 1984 . There are two alternative explanations: either these highly exposed but seronegative patients represented people relatively insusceptible to infection with HTLV-
III/LAV or they represented infected people in whom the virus was truly latent and unexpressed. If the second were true the virus might become actively expressed at any later time and would be associated with late seroconversion and the usual clinical sequelae to infection. We still have a great deal to learn with this new viral infection and only the passage of time and careful study may turn speculation into fact.

We thank Dr B Bennett, Professor A Bloom Dr B Colvin, Dr P Jones, Dr P Kernoff, Dr J Lilleyman, Dr C Ludlam, Professor L Luzzatto, Dr E Preston, Dr C Rizza, Dr G Savage, Dr G Scott, and our other very many colleagues looking after haemophiliac and other patients for their cooperation and permission to present these data. We also thank the Wellcome Foundation for providing HRPO conjugated anti-HTLV-III/LAV. This study was supported in part by the Haemophilia Society, Medical Research Council, and Cancer Research Campaign.

\section{References}

1 Barre-Sinoussi F, Cherman JC, Rey F, et al. Isolation of a T-lymphotropic retrovirus from a patient at risk for acquired immune deficiency syndrome AIDS $>$. Science 1983;220:867-70.

2 Allo RC, Salahuddin SZ, Popovic M, et al. Frequent detection and isolation of cytopathic retroviruses (HTLV III) from patients with AIDS and at risk from AIDS. Science 1984;224: $500-3$.

3 Cheingsong-Popov RC, Weiss RA, Dalgleish A, et al. Prevalence of antibody human Tlvmphotropic virus type III in AIDS and AIDS-risk patients in Britain. Lancet 1984;ii:477-80.

Tedder RS, Shanson D, Jeffries D, et al. Low prevalence in the UK of HTLV I and HTLV II infection in subjects with AIDS, with extended lymphadenopathy, and at risk of AIDS. Luncel infection in subie

5 Ludlam CA, Steel, CM, Cheingsong-Popov RC, et al. Human T-lvmphotropic virus type III (HTLV III) infection in seronegative haemophiliacs after transfusion of factor VIII. Lancet 1985;ii:233-6.

5a Ball SE, Hows JM, Worsley AM, et al. Seroconversion of T cell lvmphotropic virus III (HTLV-III) in patients with haemophilia; a longitudinal study. Br Med $\mathcal{F}$ 1985;290:1705-6.

6 Carne CA, Sutherland S, Ferns RB, et al. Rising prevalence of human T-lymphotropic virus type III (HTLV III) infection in homosexual men in London. Lancet 1985;ii:1261-2.

7 Mortimer PP, Jesson WJ, Vandervelde EM, Pereira MS. Prevalence of antibody to human T lymphotropic virus type III by risk group and area, United Kingdom 1978-84. Br Med $\mathcal{J}$ 1985;290:1176-8

8 Fuchs D, Dierich MP, Housen A, et al. Are homosexuals less at risk of AIDS than intravenous drug abusers and hacmophiliacs? Lancet 1985 ;ii: 1130

Okochi K, Sato H, Hinuma Y. A retrospective study on transmission of adult T-cell leukemia virus by blond transfusions: seroconversion in recipients. Vox Sang 1984;46:245-53.

10 Clapham P, Nagy K. Weiss RA. Pseudotypes of human T-cell leukemia virus types 1 and 2 : neutralization by patients' sera. Proc Natl Acad Sci USA 1984;81:2886-9.

(Accepled 15 May 1986

\title{
Short course of steroids in home treatment of children with acute asthma
}

\author{
A DESHPANDE, SHEILA A McKENZIE
}

\begin{abstract}
A double blind, randomised, placebo controlled study of the treatment of children with acute asthma at home showed that a three day course of prednisolone hastened improvement of both asthmatic symptoms and peak expiratory flow rates. Thus all asthmatic children who present with an acute attack should be considered for treatment with corticosteroids in addition to bronchodilators not only to prevent possible deterioration but also to speed recovery.
\end{abstract}

Department of Paediatrics, Oldchurch Hospital, Romford, Essex

A DESHPANDE, MD, paediatric registrar

SHEILA A MCKENZIE, MRCP, DCH, consultant paediatrician

Correspondence and requests for reprints to: Dr S A McKenzie, Rush Green Hospital, Romford, Essex RM7 OYA.

\section{Introduction}

Corticosteroids are now generally accepted to be of value in the management of patients admitted to hospital with acute severe asthma. ${ }^{1}$ Their value for patients not admitted to hospital is less clear. These patients have by implication less severe asthma at the time of presentation, and it might be argued that improvement would occur just as quickly with corticosteroid treatment as without it. We conducted a study to examine whether a three day course of prednisolone speeded recovery in children with an acute episode of asthma managed at home. We assessed both symptomatic improvement and improvement in airways obstruction as measured by changes in peak expiratory flow rate (PEFR).

\section{Patients and methods}

Children with asthma who attended the paediatric chest clinic were eligible for admission to the study provided they could use a peak flow meter. 
Children who presented in the casualty department with an acute wheezy episode and with a PEFR of $15-80 \%$ of a baseline value that had been obtained when they were well were, together with their parents, invited to take part in the study. Symptoms over the previous 24 hours were recorded with a scoring system that gave a score of $0-3$ for cough and for wheeze during both the day and the night; thus the maximum score was 12 .

After measurement of the PEFR each child received one dose of nebulised salbutamol ( $2 \mathrm{mg}$ in $5 \mathrm{ml}$ physiological saline) and was then given, in a randomised, double blind manner, a three day course of either prednisolone or an identical placebo to take home. Each was asked to continue his usual dose of inhaled bronchodilator every four hours until returning for review on the fourth day. The day of presentation was taken as day 1 . The dose of prednisolone (or identical placebo) was $2 \mathrm{mg} / \mathrm{kg}$ on day $1,1 \mathrm{mg} / \mathrm{kg}$ on day 2 , and $0.5 \mathrm{mg} / \mathrm{kg}$ on day 3 . Each child was given a peak flow meter (Airmed Inc) and asked to record the PEFR in the morning and evening before treatment with their bronchodilator until the day of return, day 4 . All were asked to continue any other treatment they had been taking and to record it.

On the day of return symptoms were recorded for the previous 24 hours in the same way as they had been at presentation.

Number of children-The number of children taking each treatment (n) required to enter the study to show between the two groups a $20 \%$ difference (d) in mean improvement (change in PEFR) on day 3 was calculated according to the guidelines of Pocock ${ }^{2}$ as $n=\left(2 \sigma^{2} / d^{2}\right) \times f(\alpha, \beta)$, where $\sigma=$ standard deviation of PEFR obtained from previous studies $(=20 \%)$, $\alpha=0.01, \beta=0.05$, and $f(\alpha, \beta)=17 \cdot 8$. Thus 36 patients would have to be enrolled for each treatment to show a clinically important difference in PEFR (20\%) with $95 \%$ certainty that such a difference would be detected at the $1 \%$ level of significance. We considered that in our practice we should be able to enrol such a number of patients in a reasonable period of time (two years). We elected to break the code after the entry of 50 patients for interim analysis and to stop the study if treatment showed significant improvement at $\mathrm{p}<0.01$.

Analysis of results - Wilcoxon rank sum tests for paired and unpaired data were used to analyse the symptom scores, and Student's $t$ tests for paired and unpaired data were used for the measurements of PEFR. For each child PEFR was expressed as a percentage of the best value that he could achieve when completely well; this value was obtained from the clinic notes.

\section{Results}

After 50 patients had entered the study we broke the code; review of the diary cards indicated that six could not be considered because they had been incorrectly completed. Thus we analysed the results of 44 patients, 21 of whom had received placebo and 23 the drug. The mean age of the patients was 10.5 (range 5-15) years; 33 were boys and 11 girls. Eleven patients (six given placebo and five given prednisolone) continued to take

Improvements in peak expiratory flow rate (PEFR) from baseline values during treatment with prednisolone and placebo. Figures in parentheses are $95 \%$ confidence limits

\begin{tabular}{|c|c|c|c|c|}
\hline & & \multicolumn{2}{|c|}{ Mean change in PEFR (\%) } & \multirow{2}{*}{$\begin{array}{l}\text { Mean improvement with } \\
\text { prednisolone compared with } \\
\text { placebo }(\%)^{\star}\end{array}$} \\
\hline & & $\begin{array}{l}\text { Placebo } \\
(n=21)\end{array}$ & $\begin{array}{l}\text { Prednisolone } \\
\quad(n=23)\end{array}$ & \\
\hline Day 2 & $\begin{array}{l}\text { Morning } \\
\text { Evening }\end{array}$ & $\begin{array}{r}1 \cdot 6(-5 \cdot 4,8 \cdot 6) \\
11 \cdot 0(5 \cdot 3,16 \cdot 7)\end{array}$ & $\begin{array}{l}18 \cdot 0(11 \cdot 3,24 \cdot 7) \\
31 \cdot 0(23 \cdot 9,38 \cdot 1)\end{array}$ & $\begin{array}{l}16 \cdot 0(6 \cdot 4,25 \cdot 6) \\
20 \cdot 0(11 \cdot 0,29 \cdot 0)\end{array}$ \\
\hline Day 3 & $\begin{array}{l}\text { Morning } \\
\text { Evening }\end{array}$ & $\begin{array}{l}11 \cdot 0(4 \cdot 0,18 \cdot 0) \\
18 \cdot 0(11 \cdot 9,24 \cdot 1)\end{array}$ & $\begin{array}{l}26 \cdot 0(19 \cdot 7,32 \cdot 3) \\
43 \cdot 0(35 \cdot 1,50 \cdot 9)\end{array}$ & $\begin{array}{l}15 \cdot 0(5 \cdot 6,24 \cdot 4) \\
25 \cdot 0(15 \cdot 0,35 \cdot 0)\end{array}$ \\
\hline
\end{tabular}

*Calculated as mean change in PEFR during treatment with prednisolone minus mean change during treatment with placebo.

beclomethasone, 11 (five and six, respectively) cromoglycate, and five (three and two) oral theophylline.

Symptom scores at the time of presentation did not differ significantly between the two groups, the median score being seven in those who took the steroid and five in those who took placebo. At the end of treatment symptoms in both groups had improved significantly (median improvement five in the treatment group $(p<0.001)$ and three in the placebo group $(p<0.01))$. Comparison of the improvements between the two groups showed that those who had received prednisolone had a more favourable outcome than those who had received placebo $(p<0.001)$.

There was no significant difference in mean PEFR between the two groups at the time of presentation (49 (SD 17)\% in those who received placebo and 46 (19)\% in those who received prednisolone). The table shows the improvements in PEFR in the morning and evening of days 2 and 3. The mean improvements in the group who received steroids were significantly greater than those in the group who received placebo. The figure shows the

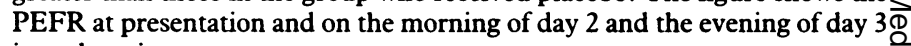
in each patient.

No child in either group had to return to hospital during the period of the study, but five children were admitted when they returned on day 4 because they had shown little or no improvement. All five had received placebo.

\section{Discussion}

It would be impossible to show conclusively that the early $\overrightarrow{\vec{F}}$ treatment of an acute attack of asthma with corticosteroids reduceso the mortality from asthma. There is good evidence, however, that corticosteroids hasten recovery from severe asthma. In a controlled $\overline{\bar{m}}$ trial conducted by Fanta et al a group of adult inpatients with a $\mathbb{\Phi}$ severe attack treated with hydrocortisone recovered more quickly than a similar group treated with placebo. ${ }^{3}$ By 12 hours the mean ${ }_{-}^{\infty}$

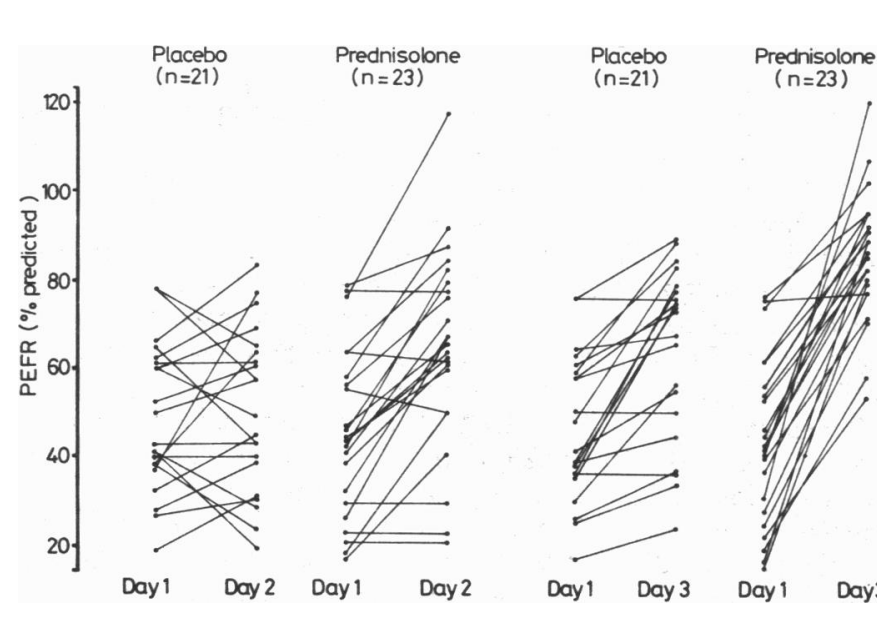

Peak expiratory flow rate (PEFR) at presentation and on morning of day 2 andô evening of day 3 in patients given placebo and patients given prednisolone.

change in the forced expiratory volume in one second was significantly greater in the group treated with hydrocortisone than? the group treated with placebo. In our study corticosteroid treatment also hastened recovery in a group of children with much less severe asthma (although it was troublesome enough for them to have $:-$ sought medical attention). The study was designed to include 3 . sufficient children for it to detect reliably an objective improvement $\delta$ in airways obstruction as assessed by measurements of PEFR as well as to evaluate subjective improvement in symptoms.

Some comment should be made about the PEFRs. It has been noted that children who are practised in using peak flow meters $\odot$ record higher PEFRs than would be expected from values derived $\frac{D}{O}$ from population studies. ${ }^{4}$ Accordingly, in the present study we decided, as others have done, ${ }^{5}$ to use as the baseline value the best ${ }_{0}$ PEFR recorded when the child was well.

A previous study suggested that when a doctor is consideringo whether to keep a child with acute asthma in hospital a PEFR ato presentation of over $25 \%$ of the expected value is a reasonable guide $\mathbb{\Phi}_{\mathbb{\infty}}^{\leftarrow}$

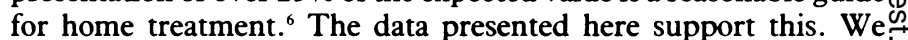
suggest that children with PEFRs at presentation in the range 15- 0 $25 \%$ of the expected value are probably in a borderline category for

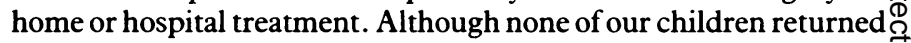
to hospital during the study, five from the placebo group were $\stackrel{\mathbb{Q}}{\mathbb{Q}}$ admitted at the end of the study. It is not uncommon for patientso with acute asthma to return to hospital after treatment with only a nebulised $\beta$ agonist. Our results suggest that early treatment of sucho patients with corticosteroids would make return to hospital less likely and might well prevent dangerous deterioration. 
Corticosteroid treatment for asthma has been regarded as potentially dangerous because of the risk of side effects. ${ }^{7}$ Studies in children with acute asthma who had received an eight day course of methylprednisolone compared with a similar group of children who had received placebo showed that in both groups adrenal responsiveness was decreased seven days after the end of treatment; the decrease was no greater in the group given methylprednisolone than in the group given placebo. ${ }^{8}$ It is thus highly unlikely that a single three day course of corticosteroids would have any adverse effect. Provided that the day to day treatment of patients with asthma is properly supervised the need for repeated courses of corticosteroids for acute attacks should be minimal.

\section{References}

Anonymous. Acute severe asthma [Editorial]. Lancet 1981;i:313-4

2 Pocock SJ. Clinical trials. Chichester: John Wiley and Sons, 1983:123-41.

Fanta CH, Rossing TH, McFadden ER. Glucocorticoids in acute asthma: a critical controlled trial. Am J Med 1983;74:845-51.

Wilson N, Silverman M. Controlled trial of slow-release aminophylline in childhood asthma: are short-term trials valid? Br Med f 1982;284:863-6.

5 Lulla S, Newcomb RW. Emergency management of asthma in children. F Pediatr 1980; 97:346-50. 6 McKenzie SA, Edmunds AT, Godfrey S. Status asthmaticus in children: a one year study. Arch Dts Child 1979;54:581-6.

Luksza AR. Acute severe asthma treated without steroids. Br 7 Dis Chest 1982;76:15-9.

8 Shapiro GG, Furukawa CT, Pierson WE, et al. Double-blind evaluation of methylprednisolone versus placebo for acute asthma episodes. Pediatrics 1983;71:510-4.

Accepted 13 May 1986

\title{
Technetium-99m autologous phagocyte scanning: a new imaging technique for inflammatory bowel disease
}

\author{
W PULlMAN, R HANNA, P SUllivaN, J A BOOTH, F LOMAS, WILliAM F DOE
}

\begin{abstract}
A method to determine the extent of active inflammatory bowel disease using selective labelling of autologous neutrophils and monocytes by phagocytosis of a technetium-99m $\left({ }^{99 m} \mathrm{Tc}\right)$ stannous oxide colloid is described. Unlike leucocyte scanning techniques using Indium-III ('"In), the ${ }^{99_{\mathrm{m}}}$ Tc colloid scan uses a cheap, readily available isotope, which specifically labels phagocytes. Scan results in 20 patients with inflammatory bowel disease were compared with barium examinations and colonoscopic appearances. There was close agreement in 15 of 20 patients as to the extent of mucosal disease. In four cases the scan showed more extensive disease than was suggested by barium examination. The scan showed terminal ileal Crohn's disease in three patients in whom the barium studies of the ileum had been reported as normal. In four patients with inactive disease and normal barium examinations no activity was seen on the scans.
\end{abstract}

The ${ }^{9 m}$ Tc phagocyte scan is a sensitive, reliable means of determining the extent of active inflammatory bowel disease and can be used to quantify disease activity.

\section{Introduction}

Previous studies of patients with inflammatory bowel disease have established that scanning after intravenous injection of autologous leucocytes labelled with radionuclides determines the extent of

\footnotetext{
Woden Valley Hospital, Australia

W PULLMAN, MB, BMEDSCI, registrar in department of medicine and clinical science

J A BOOTH, MB, FRACP, director of department of nuclear medicine

WILLIAM F DOE, FRCP, FRACP, professor and head of department of medicine and clinical science

Department of Nuclear Medicine, Royal Canberra Hospital, Australia

R HANNA, BAPPLSCI, DIPRPHARM, radiopharmacis

P SULLIVAN, MB, FRACP, staff specialist

F LOMAS, MB, FRACP, director

Correspondence to: Professor William F Doe, Department of Medicine and Clinical Science, John Curtin School of Medical Research, Australian National University, Woden Valley Hospital, Garran Act 2605 Australia.
}

active disease and facilitates objective assessment of activity. ${ }^{1.5}$ The technique is safe in the acutely ill patient ${ }^{t}$ and has proved beneficial in the study of the terminal ileum, for which conventional radiological and colonoscopic examinations are not always successful.

Most of the scanning techniques available use the radioisotope oxine labelled with indium-III ("III), which is expensive and is produced by a cyclotron and hence has limited availability. ${ }^{1.5}$ These factors mitigate against its widespread use in hospitals. Moreover,

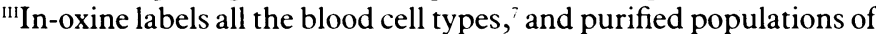
blood neutrophils must be prepared for optimal scanning. ${ }^{23}$

We recently described a new scanning technique using stannous oxide colloid labelled with technetium- $\left.99 \mathrm{~m}{ }^{4 \% \mathrm{~m}} \mathrm{Tc}\right)$ to label specifically autologous phagocytes in whole blood. ${ }^{*}$ We report the use of this readily available, inexpensive, and simple technique in scanning the intestine in patients with inflammatory bowel disease.

\section{Patients}

Twenty patients (nine men and 11 women, age range 16-70) suffering from inflammatory bowel disease (table) were studied after they had given informed consent to this study, which was approved by the Hospitals' Ethics Committee. Duration of disease ranged from two months to 15 years. Sixteen patients were diagnosed as having Crohn's disease and four as having ulcerative colitis using conventional clinical, radiological, colonoscopic, and histological criteria. Clinical disease activity was graded according to a modification of the criteria established by de Dombal as absent, mild, moderate, or severe. ${ }^{10}$ Fourteen of the 20 patients were receiving treatment with one or more of three agents: corticosteroid, sulphasalazine, and azathioprine (see table).

\section{Methods}

Autologous leucocytes (phagocytes) were selectively labelled in heparinised whole blood by phagocytosis of ${ }^{99 \mathrm{~m}} \mathrm{Tc}$ coupled to a stannous colloid ( $<2 \mu \mathrm{m}$ spheres) as described previously. ${ }^{89}$ Briefly, $20 \mathrm{ml}$ of blood was taken and incubated for one hour with $400 \mathrm{MBq}$ of ${ }^{99 \mathrm{~m}} \mathrm{Tc}$ colloid and citrate buffer. After excess colloid had been removed by centrifugation the labelled blood was returned to the patients. Immediately before abdominal scanning, which was performed at three and six hours after injection using a modern, wide field gammacamera, patients were asked to empty their bladders.

The extent of disease was determined within eight weeks of the scan by air contrast barium enema examination and, where appropriate, by small bowel 